\title{
LAND GRABBING E CRISE DO CAPITAL: POSSÍVEIS INTERSECÇÕES DOS DEBATES
}

\author{
Cássio Arruda Boechat* \\ Universidade Federal do Espírito Santo**
}

\author{
Fábio Teixeira Pitta***

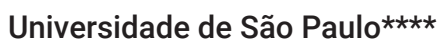

\author{
Carlos de Almeida Toledo*****

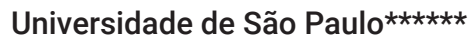

Resumo: 0 artigo aqui apresentado pretendeu realizar uma apreciação tanto do fenômeno recente denominado por land grabbing, comumente traduzido por "apropriação de terras", bem como das diferentes formulações teóricas acerca dele. Podemos sugerir que, após as crises alimentares e financeiras da primeira década do século XXI, a expansão de tal fenômeno ficou perceptível e foi responsável por fundamentar a produção de estudos e artigos inicialmente quantitativos. Uma virada mais qualitativa de abordagem do land grabbing pôde, subsequentemente, ser formulada, a qual apresentamos em linhas gerais e visitamos seus principais autores com a finalidade, porém, de alcançarmos a crítica marxista da expropriação (como dimensão formativa e reprodutiva para a compreensão do land grabbing) como prática imanente ao capitalismo como forma de sociedade. Finalmente, detivemo-nos na apropriação teórica de David Harvey para o land grabbing, para podermos relacioná-lo à compreensão deste autor da crise imanente do capital e conclusivamente, para sugerirmos alguns pontos de questionamento no que diz respeito à capacidade da própria expropriação funcionar como uma contratendência à crise atual do capital - por meio da acumulação por espoliação do ajuste espacial (HARVEY, 2005; 2011).

Palavras-chave: Land grabbing. Expropriação. Crise do capital. Espoliação. Ajuste espacial. David Harvey.

\section{LAND GRABBING AND CAPITAL'S CRISIS: POSSIBLE INTERSECTIONS OF THE DEBATES}

Abstract: The present article intended to grasp the recent phenomenon known as land grabbing as well as the different theoretical framework about it. We may suggest that after the food and financial crises of the 21 st Century's first decade the rapid expansion of such phenomenon became clear and stimulated the production of articles and researches initially based on quantitative analyses. A qualitative turn within the production over recent land grabbing was subsequently formulated. We here present this shift and its main authors in general lines, although with the purpose to achieve the Marxist critique of expropriation (as a formative and reproductive dimension to understanding land grabbing) as an immanent practice of capitalism as a social form. Finally, we focus on David Harvey's approach to land grabbing as our way to relate such phenomenon with this author's formulation of capital's immanent crisis. As a conclusion, we question the capacity of expropriation to work as a countertendency to the prevailing crisis of capital - through accumulation by dispossession and the spatial fix (HARVEY, 2005; 2011).

Keywords: Land Grabbing. Expropriation. Capital's Crisis. Dispossession. Spatial Fix. David Harvey.

*Doutor em Geografia Humana pela Universidade de São Paulo. Professor de Geografia do Centro de Ciências Humanas e Naturais/Universidade Federal do Espírito Santo. E-mail: cassio.boechat@ufes.br

** Av. Fernando Ferrari, 514 - Goiabeiras, Vitória/ES - 29.075-910. Telefone: (27) 4009 - 2523.

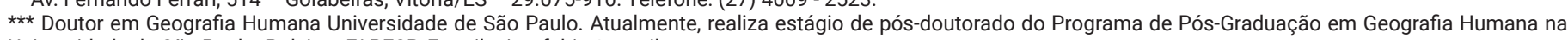
Universidade de São Paulo. Bolsista FAPESP. E-mail: pitta.fabio@gmail.com

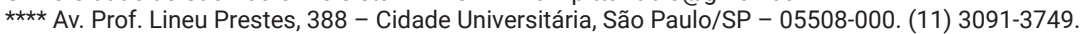

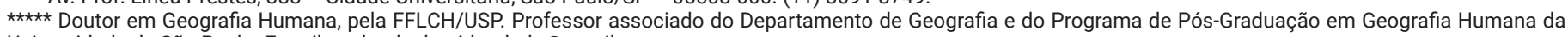
Universidade de São Paulo. E-mail: carlosdealmeidatoledo@gmail.com

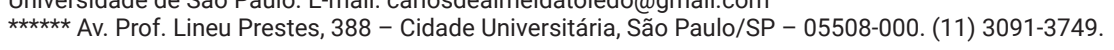


Resumen: El artículo aquí presentado pretendió realizar una apreciación tanto del fenómeno reciente denominado por land grabbing, que suele ser traducido por "apropiación de tierras", así como de las diferentes formulaciones teóricas acerca del mismo. Podemos sugerir que después de las crisis alimentarias y financieras de la primera década del siglo XXI, la expansión de esto fenómeno se quedo perceptible y fue responsable por fundamentar la producción de estudios y artículos inicialmente cuantitativos. Subsecuentemente, un cambio más cualitativo de abordaje del land grabbing se tornó posible, lo cual presentamos en líneas generales y visitamos sus autores principales aunque con la intención de llegarnos a la crítica marxista de la expropiación (como dimensión formativa y reproductiva para la comprensión del land grabbing) como practica inmanente al capitalismo como forma de sociedad. Finalmente, nos detuvimos en la apropiación teórica de David Harvey para el land grabbing, para podernos relacionarlo a la comprensión de este autor para la crisis inmanente del capital e, conclusivamente, para sugerirnos algunos puntos de cuestionamiento en lo que se refiere a la capacidad de la propia expropiación funcionar como una tendencia contraria a la crisis actual del capital - por medio de la acumulación por espoliación del ajuste espacial (HARVEY, 2005; 2011).

Palabras clave: Land grabbing. Expropiación. Crisis del Capital. Espoliación. Ajuste Espacial. David Harvey.

\section{Introdução}

Este artigo procurou retomar o debate recente sobre land grabbing, que compõe nos últimos anos, segundo Cotula (2012) e Sauer e Borras Jr. (2016), uma "corrida na produção acadêmica" para tentar dar conta de interpretar a "corrida mundial por terras" que teria se inaugurado como respostas de países, empresas e fundos de investimentos às crises alimentar, energética, ambiental e financeira, dos anos 2000 , agravadas a partir de 2007/2008.

Observamos, em nossa retomada dessa profusão de textos, livros e artigos sobre o tema, a existência de duas fases bem marcadas na referida produção, sendo a primeira pautada pelas tentativas de quantificar 0 fenômeno e a segunda caracterizada por uma "virada qualitativa", a buscar elementos teóricos, políticos e metodológicos para melhor interpretar (ou para gerenciar) o processo. Dentro dessa segunda fase da produção acadêmica sobre land grabbing destacamos a emergência de "narrativas de crise", a articular a expansão da apropriação mundial de terras como resposta às dimensões de crise acima aludidas. Com isso, observamos, sobretudo pela incorporação parcial da teorização de D. Harvey sobre a "acumulação por espoliação" ou sobre o "ajuste espacial", a possibilidade de um diálogo dessa literatura recente com a teorização marxista sobre o desenvolvimento crítico do capitalismo.

Há, assim, uma sugestão de uma "virada crítica" dentro da "virada qualitativa" na "corrida na produção acadêmica" sobre land grabbing, o que não significa que não haja críticas recorrentes às práticas de land grabbing além da literatura que flerta com a perspectiva marxista, embora encontremos nesta última perspectiva uma possibilidade de uma interpretação mais aprofundada e sistemática sobre a relação entre desenvolvimento e crise. Por isso, desdobramos nas seções finais deste artigo um entendimento sobre a teoria marxiana da crise e localizamos, dentro dessa matriz interpretativa, as leituras particulares de D. Harvey.

\section{Os debates sobre land grabbing}

\section{A questão da quantificação}

De início os números, mas quais números e o que representam? Vejamos. O assombro (ou a tentativa de promovê-lo) com relação à corrida recente para a aquisição de terras ao redor do mundo vem sendo mensurado de maneiras diversas. E com implicações a serem debatidas.

A fonte de dados mais recorrentemente acionada tem sido o relatório de 2010 do Banco Mundial, posteriormente publicado como Rising Global Interest in Farmland - can it yield sustainable and equitable benefits? (DEININGER et al., 2011). Nele, os autores advogam uma visão que pende a um estímulo aos investimentos em aquisições de terras em locais mapeados como possuindo terras subutilizadas e passíveis de serem adquiridas a preços baixos e com boa fertilidade e localização. Antes do debate sobre as implicações de tal roteiro para o "banquete nos trópicos", reitera-se usualmente o levantamento da existência de um boom na comercialização de terras agricultáveis a partir de 2008. E o número representativo apresentado pelos autores apontava para um interesse expresso na comercialização de terras no mundo em torno de 56 milhões de hectares, apenas entre 2008 e 2009 (DEININGER et al., 2011).

Outros estudos permitem-nos compilar a abrangência da discrepância. Enquanto a primeira publicação do relatório do Banco Mundial estimava uma área global total de 43 milhões de hectares sendo efetivamente negociada, estudo da The International Land Coalition (ILC) reportava um número de 81 milhões de hectares apropriados na última década, ao passo que outra estatística da Oxfam apontava 227 milhões de hectares transacionados no período (White et al., 2012, p. 620). L. Cotula (2012, p. 652) mostraria os mesmos estudos com números distintos e com destinações geográficas desiguais dos investimentos: ILC indicando aquisições 
entre 51 e 63 milhões de hectares em 27 países africanos, entre 2008 e 2010; Deninger et al. (2011) apontando 56,6 milhões de hectares negociados em 81 países ao redor do mundo, entre outubro de 2008 e agosto de 2009, a partir de dados de GRAIN; e a Oxfam atestando ao redor de 67 milhões de hectares transacionados em todo o mundo entre 2001 e 2010.

De todo modo, a imponência da mudança do patamar de negociações saltava aos olhos e o impacto do dado empírico representava antes de tudo um chamado à atenção para algo expressivo e preocupante. S. Sauer e S. Leite (2012) captaram bem essa possibilidade ao indicar, embasados no referido relatório do Banco Mundial, que enquanto a média anual de negociações com terras no mundo era de cerca de 4 milhões de hectares até 2008, a partir de então e até outubro de 2009 este número saltara para 43 milhões de hectares. S. Sassen (2013) tampouco se furtaria a se valer do importante expediente, apontando que, entre 2006 e 2012, mais de 200 milhões de hectares foram adquiridos por firmas e governos estrangeiros ao redor do mundo.

Porém, não poderiam as variações consideráveis nos dados implicar questionamentos dos estudos em si? A busca pelos chamados killer facts não seria desnecessária face à gravidade e à urgência de análises das implicações do monopólio sobre a terra em qualquer escala? $\mathrm{E}$, ainda, o que há de novo no movimento global de aquisições de terras é mesmo sua intensidade nova ou existem outros elementos qualitativos a se considerar? Antes, todavia, de avançar sobre tais questionamentos, mais séria do que a questão sobre a discrepância dos dados totais cabe se ponderar sobre a própria produção de dados em geral.

Duas organizações vêm se dedicando a realizar tais levantamentos que, por sua vez, vêm servindo de fonte de dados para pesquisas acadêmicas e matérias jornalísticas. Trata-se dos estudos feitos pela ONG internacional GRAIN e pelo portal na internet The Land Matrix. Os estudos da GRAIN se centraram no período entre 2007 e 2011, perdendo espaço entre as outras frentes de atuação da organização, expressas em seu website (<www.grain.org>), enquanto o outro portal (<landmatrix.org $>$ ) segue recebendo informações e as compilando, produzindo um banco de dados importante.

As diferenças ${ }^{1}$ entre as fornecedoras de dados para

11. Scoones, R. Hall, S. Borras Jr., B. White e W. Wolford (SCOONES et al., 2013, p. 470-472) reconhecem que ambas as iniciativas deram importantes contribuições para o debate sobre land grabbing, mas que as duas têm sérias limitações e problemas. De todo modo, os autores apontam suas diferenças ao observar que a parceria que organiza The Land Matrix, iniciada pela The International Land Coalition (ILC) e se desdobrando em outras iniciativas, adotou a estratégia de crowd-sourcing para identificar negociações de terras, sendo que as submissões de informações por terceiros seriam checadas e confirmadas e só depois entrariam no grande banco de dados. A estratégia de GRAIN, por outro lado, foi a de fazer pesquisas na internet e compilar registros, amplamente baseada em matérias de imprensa sobre negociações internacionais de militantes, acadêmicos e políticos também se observam nas suas motivações declaradas ao levantar, organizar e disponibilizar tais dados sobre aquisições de terras. Desse modo, diante do espanto com o fenômeno de land grabbing e a sensação de urgência, criou-se um contexto primordial para a pesquisa engajada. Neste, GRAIN se posicionou explicitamente como não se propondo a fazer uma pesquisa neutra, mas tendo o objetivo de "compilar a melhor e mais útil informação" para apoiar respostas de comunidades locais e redes de ativistas contra o fenômeno (<www.grain.org >). Por sua vez, a parceria The Land Matrix declararia buscar promover a transparência e fornecer dados abertos sobre decisões tomadas sobre terras e investimentos, como passo para um melhor entendimento sobre o que estava ocorrendo. Scoones et al. (2013, p. 472), todavia, enxergam um mesmo comprometimento político, embora o papel político da pesquisa seja mais explícito em GRAIN do que em The Land Matrix. Assim, ambas se tornaram fontes recorrentemente acessadas, inclusive influenciando politicamente o debate.

No entanto, B. White, S. Borras Jr., R. Hall, I. Scoones e W. Wolford (WHITE et al. 2012, p. 620) apontariam que, apesar de haver certa concordância em relação à definição de land grabbing, à necessidade e às maneiras de mensurá-lo, as grandes negociações com terras são usualmente secretas e ninguém sabe exatamente quanta terra foi adquirida. C. Oya (2013, p. 506-507) vai além e atesta que a base empírica bruta sobre land grabs não deriva de levantamentos quantitativos em larga escala sobre propriedades fundiárias nem de qualquer número considerável de entrevistas diferenciadas. Desse modo, este autor cita quatro problemas dos "números" sobre land grabbing.

O primeiro problema da mensuração seria relativo a se tomar dados publicados na imprensa como fatos a serem incorporados nos bancos de dados como Grain e Land Matrix, de modo a haver uma "complex mix of facts and 'factoids"' (OYA, 2013, p. 506). O segundo advém da dificuldade mesma de se coletar dados sobre uso da terra, tanto aqueles coletados por fontes oficiais como os coletados pelos próprios pesquisadores, comprometendo as pesquisas e as comparações entre países. 0 terceiro problema estaria no caráter enviesado dos bancos de dados sobre land grabs, como, por exemplo, na maior atenção dada aos casos ocorridos na África ou àqueles em que o governo e empresas chineses estão envolvidos, negligenciando o que vem ocorrendo em outras partes e também a importância de investidores domésticos que, embora sejam os atores principais nessa corrida, aparecem de forma menos espetacular nos noticiários

terras, disponibilizando as informações num banco de dados aberto a qualquer interessado, bem como publicando relatórios ocasionais.

Uma compilação de dados, explicação de metodologias e primeira sistematização sobre as práticas de quantificação de land grabbing pode ser encontrada em Cotula (2012). 
e na percepção nacionalista geral. Por fim, o quarto problema resultaria de uma quase completa ausência de trabalhos de confirmação dos dados coletados, e, quando há pesquisas mais rigorosas, estas parecem indicar uma grande distância entre as intenções de investimento em terras e os reais investimentos sacramentados e efetivamente feitos (OYA, 2013, p. 506-509).

Diante do referido cenário, Oya (2013, p. 508 - tradução nossa) afirma haver uma espécie de "bola de neve" que parte das informações contidas nos bancos de dados de Land Matrix e GRAIN, sendo utilizadas por pesquisadores e ativistas que fazem reclamações por meio de grandes números, geralmente apontando os casos dos grandes "apropriadores" (grabbers) de terras. Isso, então, alimenta a imprensa que produz manchetes espetaculares para atrair seus leitores. A partir de então, as matérias se tornam fontes para livros e para a literatura acadêmica, e assim por diante sem que ninguém reconheça que os "dados" são "fluidos, imprecisos e sujeitos a mudar após verificação".

Corroborando a lista de problemas elencados, Oya (2013) e Scoones et al. (2013, p. 472-475 traduções nossas) concluiriam ter se constituído uma "circularidade de referências", "produzindo uma metadiscussão sobre negociações com terras bastante descolada da verificação in loco", na qual a dupla contagem de negociações se soma a casos como o do bizarro embasamento da pesquisa recorrentemente citada do Banco Mundial, apoiada basicamente num levantamento de uso da terra nas mais diversas partes do mundo feito por imagens de satélite. Trata-se, pois, de um bom exemplo da escala "distanciada" própria de uma quantificação problemática que, no entanto, não se restringia, como vimos, ao lado apologista do fenômeno.

A reiteração e a explicitação da existência desses problemas teriam, assim, levado a questionamentos que colocariam a necessidade de uma revisão de procedimentos de análise e de posturas políticas e éticas em relação ao fenômeno de land grabbing, a ponto de se apontar para o "fim da era do killer fact" e para a necessidade de "uma nova fase da pesquisa sobre land grab", aprofundando o debate com a sociedade civil (SCOONES et al., 2013, p. 480).

\section{A virada qualitativa}

Tanto Oya (2013) como Scoones et al. (2013), mas também White et al. (2012), apontam ter ocorrido uma mudança entre uma primeira leva de estudos sobre land grabbing mais superficiais e apressados, entre 2008 e 2012, e uma segunda em que se nota uma busca pelo aprofundamento de questões suscitadas anteriormente. Na primeira fase, podiam-se observar dois tipos de contribuições principais: teorizações sem provas empíricas sistemáticas e relatórios de campo descritivos e sem muita teorização (OYA, 2013, p. 511). A mudança qualitativa teria sido promovida e sistematizada, sobretudo, por edições especiais de periódicos como The Journal of Peasant Studies, The Journal of Agrarian Change e Globalizations e pelas conferências LDPI (Land Deal Politics Initiative), mas envolveria também uma posição diferenciada no sentido de uma crítica qualitativa às aquisições de terras em larga escala da parte de organismos internacionais, como a FAO/ONU (Organização das Nações Unidas para Agricultura e Alimentação) e o próprio Banco Mundial, e uma compreensão da variedade de resistências que o fenômeno provoca, pondo em questão o próprio entendimento dele como unívoco e consensual (HALL et al., 2015, p. 468).

Segundo os pesquisadores que lideraram esta guinada de aprofundamento sobre as referidas questões - principalmente, Saturnino M. Borras Jr., Ruth Hall, Ian Scoones, Ben White e Wendy Wolford -, tratavase de constituir uma plataforma e uma rede para gerar evidências sólidas por meio de pesquisas de campo detalhadas que fizessem uma ponte entre o pensamento teórico-acadêmico com a militância, ao que se somava a destinação de uma série de bolsas de estudos e a organização de congressos. A motivação, desse modo, era explicitamente a de se promover uma virada qualitativa:

\footnotetext{
In this context, in-depth and systematic enquiry that takes into account the political economy, sociology and ecology of contemporary land deals is urgently needed. It is for this reason that the five of us came together and launched the Land Deal Politics Initiative (LDPI) (...), all of us are members of the editorial team of the Journal of Peasant Studies (JPS). Thus there is solid basis for collaboration between LDPI and JPS on this team, leading to fruitful initiatives such as this JPS Forum on Global Land Grabbing (...). (BORRAS JR. et al., 2011, p. 210)
}

Numa primeira escala, pode-se observar um aprimoramento qualitativo da própria compilação e publicação de dados sobre aquisições de terras em larga escala. 0 portal The Land Matrix, por exemplo, passaria a indicar as fontes de suas informações e as discerniria entre intenções de investimentos e investimentos efetivamente concretizados, qualificando melhor, dessa maneira, os dados disponibilizados.

Em outra escala, importantes organizações como o G8, o grupo das principais economias mundiais, por meio do Banco Mundial, e a ONU (Organização das Nações Unidas), por meio da FAO, passariam a incorporar em documentos oficiais e diretrizes destinados a países 
e investidores particulares parte das preocupações levantadas pelas pesquisas e pelos ativistas contra as grandes aquisições de terras $^{2}$.

Para R. Hall, M. Edelman, S. Borras Jr., I. Scoones, B. White e W. Wolford (HALL et al., 2015, p. 479), as bases políticas e ideológicas que unem e dividem as fileiras de atores sociais lidando com as negociações com terras foram se organizando em três formas de regulação diversas, visando: regular para facilitar; regular para mitigar impactos negativos (e maximizar oportunidades) ou regular para bloquear e reverter land grabs ${ }^{3}$. Constituíase, desse modo, uma "corrida pela governança fundiária", amparada por tais documentos acima e pelas pesquisas feitas (MARGULIS; MCKEON; BORRAS JR., 2013).

Porém, uma transformação na produção teóricoacadêmica sobre o fenômeno merece de nossa parte uma atenção mais detida, embora não deixando de reconhecer as relações desta com as dimensões acima aludidas.

O Relatório do Banco Mundial, anteriormente aludido

${ }^{2}$ Em 2012, o G8 lançou o documento New Alliance for Food Security and Nutrition, colocando em sua agenda a necessidade de transparência e responsabilidade sobre investimentos em terras. Em maio do mesmo ano, o Comitê de Segurança Alimentar da FAO lançou o Voluntary Guidelines on Responsible Governance of Tenure of Land, Fisheries and Forest in the Context of National Food Security, saudado por Scoones et al. (2013, p. 475) como extraordinária conquista a exigir posicionamentos e respostas de governos, de entidades da sociedade civil e de investidores.

Outro documento importante foram os Principles for Responsible Agricultural Investment that Respect Rights, Livelihood and Resources (RAI), proposto pela FAO, lançado pelo Fundo Internacional para o Desenvolvimento da Agricultura (IFAD), pela Conferência das Nações Unidas sobre Comércio e Desenvolvimento (UNCTAD) e pelo Banco Mundial. Elencando sete princípios, o documento foi criticado, por um lado, da parte de governos interessados seja em vender ou em comprar terras, por não ser suficientemente inclusivo, e, por outro lado, da parte de movimentos e organizações sociais, por se constituir como espécie de checklist para validar investimentos (DE SCHUTTER, 2011, p. 254). Os dois documentos foram considerados (HALL et al. 2015, 479) como apresentando parâmetros internacionais diversos para os agentes envolvidos nos debates sobre land grabbing. Enquanto o primeiro foi tratado como "o mais importante fundamento global em relação aos direitos à terra e seus recursos naturais", o segundo aparecia como "um parâmetro para a autorregulação dos investidores".

A eles se somaram os Principles for Responsible Investment in Agriculture and the Agro-food System (RIA), pela FAO, em 2014, que seguiu a adoção do Voluntary Guidelines e explicitamente se contrapunha como alternativa ao RAI patrocinado pelo Banco Mundial. O histórico do Banco Mundial em estimular países em desenvolvimento a aceitar investimentos estrangeiros, diminuindo protecionismo e fiscalização, corroboraria as suspeitas da militância e de pesquisadores, mas, por outro lado, a adoção de um discurso preocupado com as implicações dos investimentos que passam por aquisições em larga escala de terras representava, de algum modo, uma reação dessas instituições à primeira leva de pesquisa e de reclamações acerca do fenômeno de land grabbing.

${ }^{3}$ Por exemplo, o relator da ONU sobre direito à alimentação, 0 . de Schutter (2011, p. 254) afirmaria que, à medida que o debate sobre land grabbing girava em torno de sua regulação, tratava-se de uma insuficiente posição aparentemente neutra, possivelmente favorável aos investimentos em aquisição de terras em larga escala. Insuficiente posição porque, por outro lado, ele defendia uma análise aprofundada dos custos de oportunidade subjacentes, uma vez que tais investimentos implicam um modelo de produção em larga escala para a exportação em detrimento da agricultura familiar e das populações locais e sua segurança alimentar. no que tange aos números de aquisições de terras em larga escala no mundo, constitui um parâmetro também interpretativo do fenômeno, implicando, como se sabe, incentivos a grupos econômicos e a formas estatais de regulação. Este Relatório (DEININGER et al., 2011, p. 76), em sua essência, constituir-se-ia num influente guia para "terras disponíveis" no mundo e concluía haver cerca de 446 milhões de hectares não devidamente cultivados em terras agricultáveis e não florestais, em áreas pouco habitadas, com menos de 25 pessoas por km².

A noção de "lacuna produtiva" (yield gap) era aí acionada para calcular o quanto se podia incrementar na produção segundo as condições dadas e valendo-se das melhores condições técnicas disponíveis. Isso levava a uma classificação de países segundo uma tipologia que variava entre aqueles que teriam: a) pouca terra disponível e baixa lacuna produtiva (como China, Japão, países do Oriente Médio etc.); b) terras disponíveis e baixa lacuna produtiva (como Brasil, Uruguai e Argentina e outros do Leste Europeu); c) pouca terra disponível e alta lacuna produtiva (como alguns países da África e da América Central); e d) terras disponíveis e alta lacuna produtiva (como Sudão, Etiópia, Moçambique, Tanzânia e outros) (DEININGER et al., 2011, p. 86-93). Com isso, ficava clara a observação lógica de uma ação de governos e empresas de (a) e ocasionalmente de (b), agindo sobretudo em (d), mas também em (b).

A positivação dessa ação, embora considerando a fragilidade institucional e social da maioria dos países tidos como alvo desta "corrida", ficava explícita nas diversas formulações sobre os benefícios a que o investimento de capitais poderia levar, sobretudo na mitigação de uma crise alimentar em potencial, mas também na alegada geração de empregos ou na de renda por meio da compra ou do arrendamento de terras, supostamente beneficiando a população (DEININGER et al., 2011, p. 71). Enquanto parâmetro interpretativo para o fenômeno de land grabbing, o Relatório do Banco Mundial seria central também num segmento de uma literatura, tornando-se alvo recorrente da crítica da produção teórica que aqui se quer abordar.

Reforçando-a e se embasando na supracitada virada qualitativa, O. De Schutter (2011, p. 251-252) observava, desse modo, um pressuposto inicial comum na maioria das análises sobre land grabbing a apontar o problema do fenômeno como localizado na falta de regulação dos Estados fracos dos países receptáculos de tais investimentos, sendo eles em geral localizados no continente africano. Ainda, ao abordar o contexto atual, esses estudos apontavam, segundo o autor, como causa do fenômeno a alta dos preços de alimentos em 2007/2008, indicando como os principais promotores das aquisições de terra em larga escala os governos e empresas da China, da Coreia do Sul, dos países do Golfo 
Pérsico e da Índia. Tais pressupostos eram sustentados por provas produzidas por ONGs e instituições de pesquisa, incluindo GRAIN e Land Matrix.

Independente da descrição e da averiguação de onde o fenômeno se dava, a perspectiva crítica que passa a se impor irá questionar alguns pressupostos como os encontrados no Relatório do Banco Mundial, acima citado. Como bem sintetiza a leitura de White et al. (2012, p. 632), a crítica compartilharia a compreensão de ausência de três fundamentos naquela leitura: a) de que as medidas de uma produção "em potencial" levam a quadros irrealistas das condições particulares de produção, inflando as expectativas; b) de que a "disponibilidade" de terras sugere não haver uso e reclamações ou disputas sobre aquelas terras; e c) de que a ideia da introdução de uma moderna agricultura ignora o passado de políticas de modernização da agricultura amplamente fracassadas ou abandonadas.

A crítica à positivação de land grabbings, tratados ali como meras aquisições em larga escala de terras, passaria, no entanto, pelo questionamento das supostas benesses trazidas pelo investimento de capital. T. M. Li (2011, p. 281-285) revisaria os pontos tratados no Relatório, indicando a pouca probabilidade de que a população local venha de fato a se beneficiar seja da venda ou aluguel de suas terras, seja do assalariamento, colocando em dúvida que o modelo produtivo do agronegócio, que se pressupunha ser instalado por meio de tais aquisições, levasse à alegada redução da pobreza.

Por fim, S. Borras Jr., C. Kay, S. Gómez e J. Wilkinson (BORRAS JR. et al., 2012) corroboram a existência de duas fases na produção sobre as aquisições de terras em larga escala, sintetizando os movimentos de aprofundamento teórico e empírico sobre o tema. Segundo os autores, passou-se a alargar o escopo da verificação de existência do fenômeno para áreas da antiga União Soviética, para o Sudeste Asiático, para a América Latina e para países do Norte. Outros estudos, citados no artigo, teriam apontado que a busca pelo controle sobre a terra derivava, principalmente, de uma busca pelo controle das cadeias globais de valor, passando-se inclusive a se teorizar sobre control grabbings, algo semelhante a críticas pretéritas sobre práticas monopolistas ora reiteradas. A busca do controle sobre as reservas de água, sobre reservas florestais (Green grabbing) e sobre os suprimentos de trabalhadores também representaram importantes desdobramentos das pesquisas. Mudanças nos regimes alimentares e na disputa mais ampla entre agricultura de pequena e larga escala se somaram a perspectivas que incluíam o conflito e a violência e aquelas que se originavam de análises mais amplas sobre 0 desenvolvimento do capitalismo global contemporâneo e a convergência de uma multiplicidade de crises: alimentar, energética, climática e financeira
(BORRAS JR. et al., 2012, p. 403).

Desse modo, ressaltamos aqui que a referida "virada qualitativa", observada tanto na própria coleta e na sistematização de dados como na preocupação de organismos internacionais e na política de um modo geral, estava referenciada num e perpassava sobretudo um aprofundamento teórico e uma ampliação de pesquisas empíricas críticas sobre o fenômeno de aquisições em larga escala de terras ao redor do mundo. Os termos desse aprofundamento teórico e empírico é que estão postos em questão e merecem ser mais bem compreendidos.

\section{Definindo o fenômeno}

A própria definição de land grabbing seria alvo de controvérsia, tendo sido, ao contrário, até então aparentemente parte de certo consenso preliminar da primeira fase de estudos.

Segundo o dicionário on-line Merriam-Webster, land grabbing é "geralmente uma mudança, uma aquisição de propriedade (como terra ou direitos de patente), muitas vezes por fraude ou pela força". Já o dicionário on-line Cambridge reitera uma dimensão da noção acima como "ato de tomar uma área de terra pela força, por motivos militares ou econômicos", mas amplia a possibilidade do seu entendimento como "ato de tomar o controle de uma parte do mercado muito rapidamente ou forçosamente". Se a expansão rápida do domínio se reitera em todas as definições acima, o objeto da dominação (terra, patentes ou parte de mercado), a maneira de proceder (por fraude, força militar ou força econômica) ou os motivos (militares ou econômicos) seguem passíveis de variação.

Quanto à tradução do termo land grabbing para o português, S. Sauer e S. Borras Jr. (2016, p. 12-13) sugerem o termo "apropriação de terras" pela sua abrangência e o leque de possibilidades interpretativas que com ele se abre, para se evitar as restrições inerentes a termos como "grilagem", "estrangeirização de terras" e "expropriação". No entanto, o uso dessas variantes tem sido recorrente, expressando a disputa pela sua interpretação.

A caracterização em si de land grabs em geral dispensaria, em certa medida, qualquer tratamento mais sistemático e profundo dentro de um quadro teórico como o do marxismo. Especificamente abordando um estudo da FAO sobre land grabs em 17 países da América Latina e do Caribe, conduzido por S. Gómez (2011), viase, por exemplo, uma definição do fenômeno como sendo de aquisições de mais de mil (1.000) hectares, com o envolvimento direto de governos estrangeiros e com impacto negativo na soberania alimentar. Atendo-se a 
essas três condições básicas, o rigor da definição levava a FAO a concluir só haver land grabbing em dois dos 17 países estudados: Brasil e Argentina.

Borras Jr. et al. (2012, p. 404-405) sugerem, por sua vez, uma definição que não seja nem tão restritiva nem muito genérica, indo além da perspectiva de análise de impactos apenas no sentido de conduzir a uma crise alimentar, mas evitando incluir na definição as formas cotidianas de expropriação ou espoliação (dispossession) por diferenciação, seja num sentido leninista ou num chayanoviano. Para evitar tais "problemas", os autores mobilizam a ideia de três aspectos definidores decisivos e interligados dos land grabbings contemporâneos.

O primeiro é a dimensão do poder envolvida no controle da terra e de outros recursos a ela associados, como a água, para extrair benefícios dele. Essa subordinação do fenômeno de land grabbing ao de control grabbing, no entanto, particulariza-se pela análise das mudanças nas formas de uso da terra, em geral associadas ao processo, envolvendo relações políticas de poder que não necessariamente implicam a expulsão de camponeses de suas terras. Nessa dimensão, os autores estão explicitamente influenciados pelas propostas de Peluso e Lund (2011).

Em segundo lugar, é necessário, de acordo com os autores, considerar a escala dos processos de aquisições de terra e há uma distinção a ser feita entre a escala das aquisições de terras propriamente ditas e a escala do capital envolvido. Inserindo essa dimensão, compreendese que há várias formas de se controlar a terra: compra, arrendamento, concessão, contrato de fornecimento, conservação florestal etc. Ademais, evita-se, assim, considerações meramente quantitativas sobre a escala das terras adquiridas, que dizem pouco ou nada sem a devida explicação sobre o seu uso produtivo, de modo que uma mesma grandeza de investimento de capital pode se materializar, por exemplo, em 300 hectares de vinhedos altamente valorizados ou em 500 mil hectares de pastagens. A esta altura, a retomada inicial dos "números" de land grabbing que expusemos mais acima adquire importante qualificação: "Our framework brings capital back into the analysis of land grabs, questioning the current prevalence of land measurement-oriented accounting" (BORRAS JR. et al., 2012, p. 404).

0 terceiro aspecto a balizar a conceituação proposta de land grabbings seria sua compreensão como parte das estratégias da dinâmica de acumulação do capital, respondendo à convergência de múltiplas crises: alimentar, energética, climática e financeira. De um lado, o investimento em terras seria uma nova e mais segura oportunidade e, de outro, seria motivado pelas crescentes necessidades dos mais novos conglomerados do capital mundial, especialmente no bloco das principais economias emergentes (BRICs) e em alguns poderosos países de renda intermediária (MICs). A ascensão de lavouras temporárias de uso variado (flex crops) entraria neste bojo representando a possibilidade de variar o investimento produtivo feito conforme as novas e dinâmicas necessidades do mercado e suas crises.

Essas características amplas e interconectadas, a compor um contexto novo, viriam a conformar uma diferenciação dos land grabs atuais em relação a movimentos anteriores de controle sobre a terra. Deriva daí a definição dos autores, que possibilitaria repensar o estudo da FAO, alargando os critérios de análise e permitindo ver a ocorrência do fenômeno não em apenas dois dos 17 países estudados, mas em 12 da América Latina e do Caribe:

\begin{abstract}
In short, contemporary land grabbing is the capturing of control of relatively vast tracts of land and other natural resources through a variety of mechanisms and forms involving large-scale capital that often shifts resource use to that of extraction, whether for international or domestic purposes, as capital's response to the convergence of food, energy and financial crises, climate change mitigation imperatives and demands for resources from new hubs of global capital. (BORRAS JR. et al., 2012, p. 405)
\end{abstract}

Vê-se, portanto, uma série de desdobramentos que recorrentemente se remete às diversas dimensões de crise, impulsionando processos e investimentos que estão na base dos land grabbings, aqui postos em questão. Retomaremos essa relação entre a qualificação dos fenômenos e as narrativas de crise na seção seguinte.

Parece-nos fundamental, porém, reconhecer antes uma origem do termo em questão num referencial crítico que permite aprofundar a compreensão sobre os fenômenos empíricos normalmente descritos ${ }^{4}$. 0 termo

${ }^{4}$ White, Borras Jr, Hall, Scoones e Wolford (WHITE et al., 2012, p. 627630) retomariam a questão, apontando a existência de seis tendências a caracterizar o movimento recente de land grabbings. Com elas, os termos da síntese acima ficam mais claros ao se remeter a fenômenos empíricos abarcados nas tendências.

A primeira tendência seria a antecipação global da insegurança alimentar, motivada pela mudança na dieta de países populosos como a China e a Índia e consolidando uma busca por suprir a demanda crescente de alimentos. A segunda seria derivada da volatilidade do preço do petróleo, levando a uma busca por uma "segurança energética", na qual a chamada "revolução dos biocombustíveis" seria reposta a uma crise energética em potencial. Reagindo a essas mudanças e tendências, haveria a integração vertical do agronegócio a produzir lavouras flexíveis, variando a sua destinação seja para a produção de alimentos, seja de rações ou mesmo de combustíveis. A terceira tendência viria dos novos imperativos ambientais, que fomentaram uma espécie de "mercado ambiental" e um discurso de separação entre povo e natureza, que os autores consideram como uma "neoliberalização da natureza". Daí adviriam novas formas de mercantilização e novas formas de governança, levando a medidas que vão desde o fomento a reservas florestais até mecanismos de compensação pela emissão de gases tóxicos e danosos, constituindo os chamados Green grabs. A quarta tendência de ascensão de mecanismos de acumulação viria do estabelecimento de corredores extensivos de infraestrutura e de Zonas Econômicas Especiais. Ambos vêm sendo financiados por organismos internacionais (BID, FMI, Banco Mundial) e mesmo por países e investidores, expandindo e melhorando a capacidade de circulação das mercadorias agrícolas e minerais e 
land grabbing, segundo White et al. (2012, p. 621), teria sido cunhado por K. Marx (1985, I, cap. 24), no capítulo d"'A assim chamada acumulação primitiva", que atribuiria à apropriação privada de largas porções de terra o primeiro passo na criação da agricultura em larga escala. Desse modo, há que se reter que a formulação original de Marx (1985) atribuía ao fenômeno ser fundamento da monopolização dos meios de produção, por meio da expulsão de populações locais, ocasionada sobretudo pelos cercamentos (enclosures) de terras comunais, produzindo simultaneamente a propriedade fundiária e o trabalhador livre. Como reconheceria J.-P. de Gaudemar (1977), constituía-se assim a dupla liberdade do trabalhador: livre negativamente das possibilidades de se autorreproduzir na terra; e livre positivamente para ir e vir, escolher onde e com quem trabalhar, ainda que não tendo a liberdade de escolher deixar de trabalhar. Para Gaudemar (1977), esse seria o processo de mobilização do trabalho. Para a literatura marxista em geral, tratavase, essencialmente, de um processo de expropriação.

No entanto, a acumulação primitiva que colocaria, por meios diversos e violentos, a extração de maisvalia como "deus único" no altar do capitalismo (Marx, 1985) veria seus métodos de aplicação serem repetidos para realidades outras, além do caso inglês tratado por Marx no referido capítulo. À reiteração de processos semelhantes de constituição da propriedade privada da terra e da mobilidade do trabalho, D. Harvey chamaria de "acumulação por espoliação" (2013, p. 121), retomando a linha de pensamento de R. Luxemburgo acerca da constante necessidade do capitalismo de incorporar elementos "externos" à sua reprodução ampliada, ou ao mercado. Nesse argumento, land grabbing seria forma recorrente de se mitigar os processos de crise do capitalismo.

\footnotetext{
Um exame mais detido da descrição que Marx faz da acumulação primitiva revela uma ampla gama de processos. Estão aí a mercadificação e a privatização da terra e a expulsão violenta de populações camponesas; a conversão de várias formas de direitos de propriedade (comum, coletiva, do Estado etc.) em direitos exclusivos de propriedade privada; a supressão dos direitos dos camponeses às terras comuns [partilhadas]; a mercadificação da força de trabalho e a supressão de formas alternativas (autóctones) de produção e consumo; processos coloniais, neocoloniais e imperiais de apropriação de ativos
}

causando impactos significativos nos mercados de terra, o que tem levado a grandes conflitos fundiários. A quinta tendência seria a criação de novos instrumentos financeiros, visando reduzir os riscos e permitindo rentabilidade a investidores a partir da preocupação disseminada de que a comida e os combustíveis (mas também os recursos naturais em geral) estão acabando. Fundos de pensão e private equities são os principais atores nesse âmbito, diversificando em meio à crise financeira seus portfólios em terras e promovendo uma agricultura baseada no modelo produtivista do agronegócio. Por fim, uma série de regras, regulações e incentivos da comunidade internacional têm se posicionado ambiguamente em relação às preocupações com as crises alimentar ambiental e energética, reiterando o incentivo ao desenvolvimento mas por vezes também apoiando a agricultura familiar e pequenos produtores. (inclusive de recursos naturais); a monetização da troca e a taxação, particularmente da terra; o comércio de escravos; e a usura, a dívida nacional e em última análise o sistema de crédito como meios radicais de acumulação primitiva. O Estado, com seu monopólio da violência e suas definições da legalidade, tem papel crucial no apoio e na promoção desses processos (...). Todas as características da acumulação primitiva que Marx menciona permanecem fortemente presentes na geografia histórica do capitalismo até os nossos dias. (HARVEY, 2013, p. 121)

Entretanto, o quanto a literatura sobre land grabbing retoma esses debates do marxismo e da questão agrária ou como se afasta deles é algo a se pensar. Na medida em que se busca a especificidade do fenômeno atual, não são muitos os autores que retomam essa história interpretativa crítica. Alguns, porém, permitem tal caminho.

Por exemplo, S. Sauer e S. Borras Jr. (2016, p. 1315) retomam esse debate, reconhecendo a importância da definição abrangente de Harvey (2013) como fundamento para o land grabbing e para green grabbings. S. Sassen $(2010 ; 2013)$ igualmente reorienta suas pesquisas anteriores (ver Sassen, 1990) sobre a política externa norte-americana implicando fluxos imigratórios nas décadas de 1970 e 1980 para práticas atuais de expulsão por meio de land grabbings, como fenômenos da acumulação por despossessão. N. Peluso e C. Lund (2011, p. 667-668) ainda encontram na literatura clássica sobre a questão agrária, desde Marx, a constância de um debate centrado em torno do controle da terra. Nessa compreensão, land grabbing é a forma primordial de se obter o controle da terra e de se promover a exclusão de outros de seu uso, sendo, entretanto, modificado por contextos em transformação e por novos atores e matrizes de interpretação dos fenômenos. As "novas fronteiras do controle da terra" seriam tema de suas análises visando à particularidade de land grabs atuais.

Tem-se, com isso, uma possível interação da literatura atual sobre land grabbing, a partir de sua "virada qualitativa", com os fundamentos de uma explicação marxista sobre o controle fundiário. Procuraremos desdobrar essa interação a partir da constatação de "narrativas de crise" orientando tal literatura e propondo um debate sobre os fundamentos da crise no interior da matriz interpretativa marxista, concluindo este artigo com o posicionamento de $\mathrm{D}$. Harvey em relação à teoria marxiana da crise, assim como com a apresentação de uma problematização acerca de tal posicionamento.

\section{Narrativas de crise}

A partir de "narrativas de crise" é que surgiram discursos como aqueles presentes, por exemplo, no 
Relatório do Banco Mundial, buscando na ocupação produtiva de "terras marginais, vazias e disponíveis", a solução para elas:

The justification for land investments on a large scale is often presented around a series of "crisis narratives", linked to growing scarcity and impending catastrophe. The underlying assumption is that the solution to such food, energy and climate "crises" lies in capturing the potentials of so-called "marginal, empty and available" lands across the globe. (WHITE et al., 2012, p. 631)

Outras narrativas de crises, no entanto, não compõem o repertório do estímulo às aquisições de terras em larga escala. Pelo contrário, a alusão a elas serve para inverter a ordem dos fatores e evidenciar que o modelo de produção em que a apropriação de largas porções de terras é pressuposta e reiterada é que deve ser pensado como causa das crises, e não exatamente sua solução.

Assim, os próprios White et al. (2012, p. 624) apontam formas contemporâneas de transição agrária que envolvem investimentos e deslocamento ou expropriação com expulsão da população sem reabsorver o seu trabalho em indústrias ou em qualquer setor da economia. A degradação social, dentro dessa "crise agrária ao redor do mundo" (2012, p. 627), viria da pobreza e da falta de alternativas para a população.

T. M. Li $(2011$, p. 295) seria ainda mais enfática em abordar a existência de uma "crise do trabalho", na qual a expropriação, ocorrendo quando ao capital interessa apenas a terra e não o trabalho, implica, no mais das vezes, falta de emprego para os expropriados, sobretudo no cenário de generalização do uso de tecnologias poupadoras de trabalho na indústria, na agricultura e na mineração, de maneira que "até trabalhos ruins estão escassos". Nesse cenário de falta de apoio do Estado, "até uma pequena fatia de terra é uma rede de segurança crucial".

No entanto, a série de casos tratados por Hall et al. (2015) permitiriam notar que a aparente melhor condição de reprodução social daqueles que permanecem na terra não poderia ser tratada de modo unívoco. Assim, a discussão sobre os "termos de uma integração adversa" pode, retomando a terminologia de Li (2011), mostrar que, mesmo quando o capital quer tanto a terra quanto o trabalho, as condições de fornecimento de pequenos produtores pode ser igualmente crítica, havendo situações em que a expropriação e o assalariamento podem aparecer como alternativas até desejadas por eles.

Por fim, é Z. W. Brent (2015, p. 672) que retoma a formulação de D. Harvey sobre o "ajuste espacial", como forma de expansão da acumulação por espoliação, para requalificar o fenômeno de land grabbing como uma reestruturação territorial, motivada pela crise do capitalismo e como forma de mitigação da mesma, acionada pelos próprios capitais em parceria com instâncias dos Estados, igualmente em crise. 0 poder territorial sobre lugares, pessoas e espaços sociopolíticos se somaria ao poder capitalista do controle do dinheiro e dos processos de acumulação. Embora reconheça a importância da formulação de Harvey, Brent defende, todavia, a busca das mediações e tensões na legitimação de práticas por meio do Estado para facilitar a acumulação de capital ${ }^{5}$.

A maneira como Harvey trataria o "ajuste espacial" como mitigação da crise é algo a ser explorado, dentro do debate sobre as "narrativas de crise". Essa crise seria, para o autor, aquela oriunda da sobreacumulação de capitais, na forma de excedentes de capital e de trabalho. A "acumulação por espoliação", privatizando terras e bens comuns, permitiria, então, liberar "ativos (incluindo força de trabalho) a custo muito baixo (e, em alguns casos, zero)" para que o capital sobreacumulado possa se apossar deles e dar-Ihes um uso lucrativo:

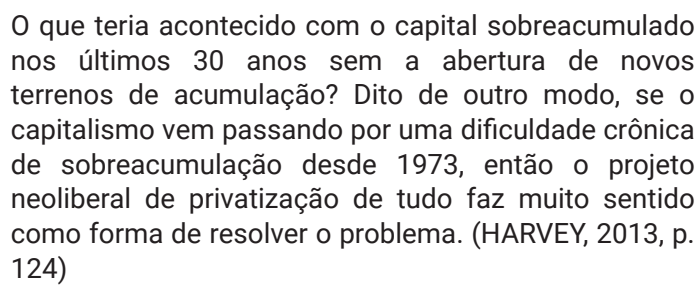

Essas outras "narrativas de crise" (crise agrária, crise do trabalho e crise do capital) permitem um olhar diferenciado para o fenômeno, que não é, desse modo, positivado como saída para o problema, mas como gerador de novas ou aprofundando crises sociais e ambientais. Conforme expusemos, o recurso à teorização de D. Harvey pela literatura recente sobre land grabbing sugere um diálogo desta com a vertente marxista de compreensão da expansão do capitalismo e das suas crises. Por isso, passaremos a nos aprofundar nesse referencial como meio de promover um aprofundamento do debate em torno das crises e, assim, repensar como interpretar o fenômeno de land grabbing. Concluiremos,

\footnotetext{
${ }^{5}$ Quem igualmente se escora na formulação de D. Harvey (aceitando-a mais do que Brent, no entanto) é S. Sassen (2010, p. 26-27), sobretudo na derivação do argumento acima, que aponta como mecanismo de mitigação da crise a injeção de matérias-primas baratas no sistema, de um lado, e a desvalorização dos ativos de capital e de força de trabalho existentes, de outro (HARVEY, 2013, p. 124-126).

Para Sassen (2010, p. 27-28), as "lógicas de extração" estariam expandindo seu domínio no capitalismo avançado. Um exemplo disso teria sido a política de modernização de países do Terceiro Mundo no pós-guerra, levando a um endividamento crônico destes. Com a crise das dívidas de inícios dos anos 1980, o serviço das dívidas teria sido especialmente perverso para países africanos e da América Latina, numa proporção em relação ao PIB muito superior ao que foi cobrado na reconstrução de países como a Alemanha e o Japão, nos anos 1940 e 1950. Sassen, com isso, observa um uso da dívida primeiro como fator de disciplinamento e depois como desvalorização dos ativos desses países, para serem reincorporados pelos capitais dos países credores, num mecanismo de "acumulação por espoliação" que incluiria práticas de land grabbing.
} 
portanto, este artigo com uma consideração teórica sobre a crise do capital e suas relações com a apropriação de terras.

\section{Aprofundando as "narrativas de crise" para repensar o land grabbing}

\section{A teoria marxiana da crise}

A ideia de que a reprodução social capitalista tende a conduzir à crise já estava presente na Economia Política clássica, embora com tratamento distinto da maneira sistêmica e inerente ao movimento do capital, tal qual Marx a elabora. R. Rosdolsky (2001, p. 315-319), por exemplo, observa a construção ricardiana de uma teoria da crise que contrapõe o uso produtivo da natureza ao seu uso industrial ${ }^{6}$, não derivando da própria dinâmica de produção industrial a imanência da queda da taxa de lucro. Retomando os apontamentos metodológicos de K. Marx (2005), o autor relaciona a teoria ricardiana ao pressuposto de T. Malthus acerca da queda tendencial da fertilidade da terra no seu uso agrícola, além da falta de distinção entre taxa de mais-valia e taxa de lucro, algo de que Marx (1986) viria a se ocupar mais no Livro III d'O capital. Na seção terceira do Livro III daquela obra é que encontraremos o debate sobre a lei da queda tendencial da taxa de lucro (Marx, 1986, III, t. 1, cap. 13), que localizamos como sendo o fundamento central da teoria da crise na obra de K. Marx ${ }^{7}$ e alvo de uma controvérsia

${ }^{6}$ Em David Ricardo (1982, p. 65-75), a expansão da necessidade social por mais mercadorias conduziria ao uso de terras de pior qualidade para a produção adicional de alimentos para a população e de matérias-primas para a indústria, evidenciando uma produtividade gradativamente menor da agropecuária. Isso acarretaria aumento da renda da terra, dado o aumento dos diferenciais de produtividade entre as terras; além disso, forçaria um aumento da quantidade de trabalho necessário à produção das mercadorias consumidas pelos trabalhadores e consequente pressão de aumento dos salários e redução da taxa de lucro, numa tendência de o sistema produtivo ser conduzido a certo "estágio estacionário".

${ }^{7}$ Antes de chegar até a concepção da crise na totalidade da reprodução capitalista, tal como abordada no terceiro livro daquela obra de Marx, devemos indicar que a possibilidade da crise já se afirmava nas suas análises anteriores. No primeiro capítulo do Livro I d'O capital, ao tratar da forma mercadoria, Marx (1985) já apontava para uma relação inerente entre forma relativa e forma equivalente, deixando entrever uma possível distinção entre os momentos da contradição interna entre valor de uso e valor. Entre outras questões, indicava-se aí a possibilidade de não se consumar a realização da mercadoria, não se tornando ela valor de uso para outro que não aquele que a produziu. De modo semelhante, no desdobramento que exterioriza a antítese interna (entre valor de uso e valor) da forma-mercadoria numa antítese externa entre mercadoria e dinheiro, os atos de compra e de venda implicam uma possibilidade da não realização do valor contido na mercadoria. Porém, essa possibilidade de crise, ainda aí analisada do ponto de vista de uma produção e circulação individualizada, adquiriria contornos efetivamente mais abrangentes na análise do dinheiro como meio de pagamento. Nesta, a distensão temporal entre os momentos de compra e venda se alargava, abrindo caminho para os posteriores desenvolvimentos teóricos marxianos sobre o crédito e evidenciando a formação de uma cadeia de interdependência, cada vez maior, entre compradores e vendedores (ou credores e devedores), a aumentar o potencial de uma falha na sequência recente $^{8}$

Apresentemos brevemente os termos da seção escrita por K. Marx e editada por F. Engels, a começar por seu título. Veja-se, a princípio, que a tão criticada formulação de uma "lei" será aí articulada à noção nada mecanicista de "tendência", de maneira a ressaltar a contradição de um processo que produz ou pode vir a produzir a sua própria crise (PRADO, 2014; MELLO, 2012). Essa tendência, indicando um caráter crítico da reprodução ampliada do capital, parece se originar, para Marx (1986), dos efeitos da própria concentração e da centralização do capital, motivados pela concorrência e acelerados pelo sistema de crédito. No entanto, na recepção marxista ao longo do século $X X$, ela pôde ser tratada em seus termos estritos, a ponto de ser criticada contemporaneamente pelo próprio D. Harvey (2015a; 2015b) como equivocadamente "monocausal", em análise confrontada por M. Roberts (2014) e por A. Kliman (2015).

Por sua vez, o próprio Marx não se furtou a apresentar possíveis e efetivas causas a contrariar aquela tendência de queda da taxa de lucro: "Deve haver influências contrariantes em jogo, que cruzam e superam os efeitos da lei geral, dando-lhe apenas o caráter de uma tendência (...)" (Marx, 1986, p. 177). No capítulo em questão (MARX, III, t. 1, 1986, cap. 14), ele cita seis causas contrariantes: a) Elevação do grau de exploração do trabalho; b) Compressão do salário abaixo de seu valor; c) Barateamento dos elementos do capital constante; d) Superpopulação relativa; e) Comércio exterior; e f) Aumento do capital por ações.

A síntese da lei da queda tendencial é, portanto, logo "bombardeada" teoricamente, pelo próprio autor, com diversas questões que compõem contratendências que, de um ponto de vista como o de M. Heinrich (2012), poderiam levar à conclusão de se tratar de uma negação da lei ou de um autor incoerente. Por outro lado, poder-se-ia argumentar ainda sobre a existência de uma "necessidade relativa" da primeira tendência,

de pagamentos levar à queda em série de compromissos firmados (MARX, l, t. 1, 1985, cap. 3).

No que se refere à transformação do dinheiro em capital, a compra de força de trabalho e seu uso produtivo apareceria, no decorrer da análise do Livro I, como condição para a valorização do capital, pela extração de mais-valia. Apareceria também como a característica fundamental da reprodução ampliada do capital (ver Marx, I, t. 2, 1985, caps. 20 a 22), de maneira a evidenciar a centralidade da valorização em detrimento da mera produção de valores de uso, que Ihe aparece como acessória, segundo um entendimento que leva à conclusão de o capital se alçar como "sujeito automático", subordinando aqueles que personificam tanto o trabalho como o próprio capital (MARX, I, t. 1, 1985, cap. 2).

${ }^{8} \mathrm{~A}$ título de breve apontamento, observamos que Harvey (1982) o consideraria como o primeiro corte da teoria da crise para posteriormente (HARVEY, 2015a; 2015b) a criticar; Heinrich (2013) o trata como uma inconsistente formulação editada por Engels e posteriormente abandonada por Marx; Kliman et al. (2013), Carchedi e Roberts (2013) e Kurz (2015) se dedicariam contra a posição de Heinrich; Kliman (2015) se esforçaria em provar que Harvey (2015a) se distancia do próprio Marx; e Kurz (1995) constrói sobre este mesmo fundamento sua formulação sobre a ascensão do capital fictício, criticada por Prado (2011). 
não se impondo necessariamente na realidade, como na proposição de leitura de J. Grespan (2012, p. 197). Ou, ainda, de um teorema superficial sobre a tendência de crise que se origina de uma tendência estrutural profunda de aumento da composição orgânica do capital, sugerindo a possibilidade de uma realização futura da "lei", conforme a sugestão de M. Postone (2008, p. 9091).

Vejamos, todavia, a lógica interna da formulação marxiana. O aumento da composição orgânica dos capitais representa uma diminuição relativa do capital variável (v) sobre o capital total (C), incorrendo numa diminuição também relativa da mais-valia extraída $(\mathrm{m})$ desse capital variável, e assim levando à queda da taxa de lucro $(\mathrm{m} / \mathrm{C})$.

A tendência progressiva da taxa geral de lucro a cair é, portanto, apenas uma expressão peculiar ao modo de produção capitalista para o desenvolvimento progressivo da força produtiva social de trabalho. (...) Como a massa de trabalho vivo empregado diminui sempre em relação à massa de trabalho objetivado, posto por ele em movimento, isto é, o meio de produção consumido produtivamente, assim também a parte desse trabalho vivo que não é paga e que se objetiva em mais-valia tem de estar numa proporção sempre decrescente em relação ao volume de valor do capital global empregado. Essa relação da massa de mais-valia com o valor do capital global empregado constitui, porém, a taxa de lucro, que precisa, por isso,

cair continuamente. (MARX, III, t. 1, 1986, p. 164)

Por se tratar de uma formulação em torno de uma relação entre os componentes que atuam sob a forma do capital, a primeira questão que se interpõe, e que contribuiu sobremaneira para posteriores divergências interpretativas, diz respeito ao fato de que o número de trabalhadores empregados e inclusive a mais-valia deles extraída pode e deve aumentar, em termos absolutos, sem anular o determinante para a lei tendencial de que estejam decrescendo do ponto de vista do capital global empregado9. Desse modo, o que é mais importante ressaltar de toda essa passagem é a maneira como a crise fundamental parece decorrer, contraditoriamente, do desenvolvimento das próprias relações sociais de produção:

A taxa de lucro não cai porque o trabalho se torna mais improdutivo, mas porque se torna mais produtivo. Ambas, elevação da taxa de mais-valia e a queda

\footnotetext{
9"O número dos trabalhadores empregados pelo capital, portanto a massa absoluta de trabalho posta em movimento por ele, portanto a massa absoluta de mais-trabalho absorvida por ele, portanto a massa de maisvalia produzida por ele, portanto a massa absoluta de lucro produzida por ele pode, por conseguinte, crescer, e crescer progressivamente, apesar da progressiva queda da taxa de lucro. Isso não apenas pode ser o caso. Tem de ser o caso - descontadas oscilações transitórias - na base da produção capitalista" (MARX, III, t. 1, 1986, p. 167). Este é outro ponto controverso que, de acordo com Roberts (2014) e Kliman (2015), Harvey (2015b) teria sugerido erroneamente que o aumento do número de trabalhadores empregados seria evidência da invalidade da "lei tendencial".
}

da taxa de lucro são apenas formas específicas em que se expressa de maneira capitalista a crescente produtividade do trabalho. (MARX, III, t. 1, 1986, p. 182)

O que se tem, com isso, é um processo que pode aparecer como "crescimento" ou "expansão" do capital ou progresso (técnico), mas que, no fundo, tende a representar uma reiteração de uma crise fundamental do capital, a estreitar a sua base de extração de mais-valia, na proporção agigantada de trabalho objetivado que não gera por si nova mais-valia.

Por outro lado, pela equalização da taxa de lucro, os capitais maiores, como maiores "acionistas" da classe capitalista de determinado setor, aparecem como tendo direito de reclamar uma maior parcela na divisão do lucro médio, exatamente por sua magnitude. 0 aumento da composição orgânica do capital aparece, ao capital individual, pois, como vantagem na competição com outros capitais por maiores massas de lucro ${ }^{10}$, embora a mesma concorrência tenda a equiparar as taxas de lucros, reduzindo-as. A mobilidade do capital e sua centralização, na análise marxiana, agiriam no sentido de reduzir as taxas de setores altamente lucrativos e de aumentar aquelas de setores saturados, menos atraentes, por meio da expulsão de capitais face à baixa rentabilidade. Por outro lado, mecanismos de controle de propriedade privada visariam monopolizar tecnologias, diferenciais de fertilidade e localização de solos e vantagens das mais diversas. ${ }^{11} 0$ quanto terão capacidade, no longo prazo, para minimizar a queda da taxa de lucro, ou o quanto essa capacidade se mostrará pontual é uma importante questão a ser pensada.

É por essa chave, portanto, que a análise de K. Marx permite compreender a contínua centralização do capital e a monopolização em diversas esferas produtivas e do mercado como "guerra" pelas massas de lucro, face à tendência imanente de queda da taxa de lucro. Essa formulação permite dar fundamentação teórica nova ao quadro de um regime alimentar corporativo e policêntrico (MCMICHAEL, 2014), ou de agigantamento dos conglomerados que agem na agricultura (BOECHAT, 2015) incluindo em suas práticas novas modalidades de land grabbing. Apresentamos, com isso, a possibilidade de um aprofundamento das "narrativas de crise", que envolve uma consideração sobre o entendimento de uma "crise imanente" do capital a motivar práticas de "espoliação" ou de "ajuste espacial". Compreender

\footnotetext{
10Também este argumento, por assim dizer, empiricista pode comprometer uma aceitação do fundamento da teoria da crise, conforme observa Kliman (2007).

${ }^{11} \mathrm{~A}$ análise dos processos de monopolização dos capitais, associados ao capital bancário, promovendo a constituição de um capital financeiro articulado a investidas expansionistas e à proteção estatal, organizou o debate acerca do imperialismo, nas primeiras décadas do século XX tendo nas obras de Hilferding (1985), Lenin (1979) e Luxemburgo (1985) seus mais importantes referenciais.
} 
a particularidade da leitura de D. Harvey sobre esse referencial é o caminho que permite a conexão do debate sobre land grabbing com o debate sobre a teoria da crise.

\section{Harvey e a teoria marxiana da crise}

Um importante leitor de K. Marx na atualidade é D. Harvey, que aceita com ressalvas a formulação marxiana. No primeiro livro em que delineia seus estudos dentro de uma perspectiva marxista, The Limits to Capital, escrito nos anos 1970, Harvey (1982) apontava a existência de três "cortes" ou níveis de crise, sendo a lei da queda tendencial da taxa de lucro (LQTTL) o primeiro deles. No entanto, os processos de desvalorização, sobretudo por meio da inflação e de crises, iriam fazer retomar patamares de lucratividade. ${ }^{12}$ Uma das formas acionadas para "exportar" a desvalorização se daria por meio da expansão territorial e da exportação de capitais. Essa perspectiva embasaria suas formulações posteriores sobre o chamado ajuste espacial (HARVEY, 2005), como já mencionamos anteriormente, e que visivelmente se articula como uma expansão territorial a mitigar os efeitos da LQTTL ${ }^{13}$. Sugerimos também acima a possibilidade de entender os fenômenos de land grabbing como parte de

\footnotetext{
${ }^{12}$ No capítulo 6 da referida obra, Harvey elabora sobre o movimento da lei geral de acumulação capitalista até a LQTTL, para no capítulo seguinte delinear sua abordagem sobre a reprodução ampliada do capital conduzir à sobreacumulação de capital. Essa acumulação excessiva seria a causa primeira de crises, exigindo um processo de desvalorização do capital. Trata-se aí de um movimento que não é meramente resultado da destruição de capitais que uma crise provoca, mas igualmente resultado da desvalorização contínua que o aumento da produtividade do trabalho reitera, a diminuir o valor adicionado às mercadorias produzidas em escala aumentada (HARVEY, 1982, p. 196-203). Esta seria uma primeira abordagem de uma teoria da crise (ou "first-cut" theory of crises). Posteriormente, após tratar das questões do capital fixo, Harvey (1982, p. 413-445) faz uma longa imersão na discussão sobre o dinheiro e suas relações com o capital produtivo, entrando no debate sobre o capital financeiro. Da desproporção aí encontrada, passando pela desvalorização materializada na inflação, Harvey circundaria uma segunda abordagem teórica fundamental da teoria da crise, já neste ponto articulando as obras de Marx às de Hilferding (1985) e de Lenin (1979). Por fim, seu olhar se voltaria para a dimensão geográfica da reprodução social sob o capitalismo, retomando as questões de Marx sobre a renda fundiária para concluir sua análise da obra marxiana nos pontos sobre a mobilidade do capital e do trabalho. A obra, todavia, iria além e debateria ainda com a teoria do imperialismo, em especial com a de Luxemburgo (1985).

${ }^{13} \mathrm{Em}$ outras obras, observamos a maneira como esse estudo de Harvey se desdobrou, especialmente nos conceitos de "ajuste espacial" e de "acumulação por despossessão" (ou "via espoliação"). Certamente, ainda, há a sua formulação consagrada da passagem do fordismo ao pós-fordismo, conformando uma nova qualidade de reprodução social, caracterizada pelo autor como marcada pela "acumulação flexível" e também pela "condição pós-moderna" (HARVEY, 1992). No que se refere à noção de "ajuste espacial", ela deriva de uma compreensão, já esboçada em Harvey (1982), de que a crise gestada na dialética interna da sociedade civil (entre capital e trabalho e na reprodução ampliada do capital) conduz à necessidade de uma expansão territorial (HARVEY, 2005). De certo modo, a consideração dessa expansão como sendo um "ajuste" evidencia um diálogo com as chamadas "causas contrariantes" à lei da queda tendencial da taxa de lucro. Devemos nos perguntar sobre os limites dessa possibilidade na obra de Harvey (ver Toledo; Boechat; Pitta, 2013), o que relaciona a discussão com a questão sobre as crises serem concebidas como cíclicas ou não.
}

um ajuste espacial de economias centrais com capitais superacumulados.

Por outro lado, em estudo mais recente sobre a crise de 2007/2008, Harvey (2011) retomaria especificamente um tratamento negativo da teorização de Marx, negando-a de maneira distinta do que parecia fazer anteriormente, numa aparente unificação das perspectivas que apontam para a inconsistência da LQTTL com aquelas que ressaltam as suas contratendências:

Marx achava que tinha identificado um meio fundamental
para explicar a queda da taxa de lucro [...]. Deslocar
o trabalho da produção era contraproducente para a
lucratividade a longo prazo. A tendência de queda dos
lucros [...] e as crises a que inevitavelmente daria origem
eram internas ao capitalismo e não eram explicáveis em
termos de limites naturais. Mas é difícil fazer a teoria de
Marx sobre a queda da taxa de lucros funcionar quando
a inovação é tanto para economizar capital ou meios
de produção (por exemplo, pelo uso mais eficiente de
energia) quanto para economizar trabalho. O próprio
Marx, na verdade, listou uma série de influências de
contratendência para a queda da taxa de lucro [...].
Esta lista é tão longa que torna a explicação de uma
lei sólida de queda de lucros uma resposta mecânica
à inovação para economizar trabalho, que permanece
uma proposta insuficiente. (HARVEY, 2011, p. 82$)^{14}$

Não precisamos assumir o lado dos defensores da inevitabilidade ou da efetividade da teoria da crise marxiana. Basta-nos apontar que a crítica de D. Harvey (2011) procura recuperar elementos de tentativa de superação daquela tendência, o que por si sugere a atuação da tendência mesma. 0 que nos parece mais importante ressaltar, para concluir, é que parece haver um movimento generalizado de aumento da composição orgânica de capitais, seja na agricultura e na mineração seja na indústria, promovendo em escala ampliada o aumento da produtividade do trabalho, ao menos em potencial, o que requer em tese uma necessidade declinante de trabalhadores e uma ascendente de matérias-primas, levando a graves consequências sociais e ambientais com a reiteração desse modelo. A tese do "ajuste espacial", assim, ao afirmar a existência de um "modelo produtivista" que se pauta pela difusão de inovações, conclui de modo contrário, por exemplo, às "sete teses sobre o mundo rural" de Buainain et al. (2014), segundo as quais a terra seria menos importante do que o capital neste modelo vitorioso. Quanto mais o capital se impõe, mais ele parece requerer a expansão territorial, e parece, pois, recolocar a importância da terra como mecanismo de mitigação da sua crise imanente. Restaria saber o quanto se poderá, nos limites históricos dados, reproduzir esse modelo e seu "ajuste espacial".

\footnotetext{
${ }^{14} \mathrm{Com}$ isso, Harvey (2011) toma partido de ambas as críticas ao esquema de reprodução ampliada crítico de Marx. Primeiramente, aponta certa indeterminação da LQTTL pela inovação economizar capital e trabalho, e, no final da citação, toma partido das "influências de contratendência", para, por cima, criticá-la como "proposta insuficiente".
} 


\section{Considerações finais}

Para concluir, podemos lembrar a formulação sobre a distinção para a agricultura entre tempo de produção e tempo de trabalho, que tendia a ser igualada pela industrialização dos processos produtivos no campo (SILVA, 1981). A principal implicação da teoria da crise marxiana é apontar uma tendência na qual, na produção altamente tecnificada e mecanizada, tempo de produção pode não significar um tempo de valorização suficiente para auferir uma taxa de lucro que remunere o sistema produtivo. A exclusão relativa e absoluta de trabalho vivo dos processos produtivos, pela sua substituição pelo trabalho pretérito e objetivado em elementos do capital constante, sugere uma dissociação crescente entre tempo de produção e tempo de trabalho. Com isso, por mais que o tempo de vida do trabalhador continue a ser expropriado dele mesmo, ele tende a ser gasto principalmente na busca por emprego ou em atividades que não necessariamente respondem pelo tempo de trabalho socialmente necessário. A sugestão de uma crise do trabalho (HEIDEMANN et al., 2014; Li, 2011) implica uma crítica ao modelo produtivista como não mais gerador de emprego e de renda, como teria sido outrora. Fica a questão do que fazer e como gestar o excedente social crescente de tempo de não trabalho.

Por outro lado, a modernização da agricultura atrelada ao projeto nacional de modernização do pós-guerra parece encontrar seus próprios limites históricos, o que não significa que o ajuste espacial não possa seguir se dando ao nível dos monopólios e das corporações, ou mesmo de países agindo estrategicamente para garantir segurança alimentar, energética ou de suprimento de matérias-primas para suas empresas. Land grabbings em busca de sobrelucros na forma de renda da terra parecem estar se dando num contexto de diversas crises, às quais procuramos sugerir aqui a existência de uma profunda e fundamental, impactando a taxa de lucro. Eles acabam por representar o aumento do capital constante das empresas, ou de seu patrimônio, que, como dissemos, acaso superacumulado, tende a se desvalorizar. Seria preciso que houvesse maneiras distintas para promover essa "valorização" do patrimônio, uma vez que, enquanto capital, de um modo geral, sua capacidade de se valorizar pela exploração do trabalho parece se tornar elemento questionável. A reiteração de mecanismos de land grabbing, assim, adquire sentido social e histórico distinto do que já teve para as fases de imposição da mobilidade do trabalho e de industrialização nacional, e seus elos com o capital financeiro precisam ainda ser buscados, o que não se pôde fazer nos limites do presente artigo. 
BOECHAT, C. A. (2015) A questão agrária e a crise da citricultura brasileira. Teoria e Cultura - UFJF, v. 10, n. 2 , p. $66-83$.

BORRAS JR., S. M.; FRANCO, J. C.; WANG, C. (2013) The challenge of global governance of land grabbing: changing international agricultural context and competing political views and strategies. Globalizations, v. 10, n. 1, p. 161-179.

BORRAS JR., S. M.; HALL, R.; SCOONES, I.; WHITE, B.; WOLFORD, W. (2011) Towards a better understanding of global land grabbing: an editorial introduction. The Journal of Peasant Studies, v. 38, n. 2, p. 209-216.

BORRAS JR., S. M.; KAY, C.; GÓMEZ, S.; WILKINSON, J. (2012) Land grabbing and global capitalist accumulation: key features in Latin America. Canadian Journal of Development Studies, v. 33, n. 4, p. $402-416$.

BRENT, Z. W. (2015) Territorial restructuring and resistance in Argentina. The Journal of Peasant Studies, v. 42, n. 3-4, p. 671-694.

BUAINAIN, A. M.; ALVES, E.; SILVEIRA, J. M. da; NAVARRO, Z. (2014) Sete teses sobre o mundo rural brasileiro. In: BUAINAIN, A. M.; ALVES, E.; SILVEIRA, J. M. da; NAVARRO, Z. (Eds.) (2014) O mundo rural no século 21. Brasília: Embrapa, p. 1.160-1.182.

BURSCH, D.; LAWRENCE, G. (2009) Towards a third food regime: behind the transformation. Agriculture and Human Values, Carolina do Sul, v. 26, p. 267-279.

CARCHEDI, G.; ROBERTS, M. (2013) A critique of Heinrich's, "Crisis Theory, the Law of the Tendency of the Profit Rate to Fall, and Marx's Studies in the 1870s". Monthly Review. Comentário, dezembro.

COTULA, L. (2012) The international political economy of the global land rush: a critical appraisal of trends, scale, geography and drivers. The Journal of Peasant Studies, v. 39, n. 3-4, p. 649-680.

DE SCHUTTER, O. (2011) How not to think of land-grabbing: three critiques of large-scale investments in farmland. The Journal of Peasant Studies, v. 38, n. 2, p. 249- 279.

DEININGER, K.; BYERLEE, D.; LINDSAY, J.; NORTON, A.; SELOD, H.; STICKLER, M. (2011) In: Rising Global Interest in Farmland: can it yield sustainable and equitable benefits? Washington: The World Bank.

FRIEDMANN, H.; MCMICHAEL, P. (1989) Agriculture and the State system: the rise and decline of national agricultures, 1870 to the present. Sociologia Ruralis, v. 29, n. 2, p. 93-117.

GAUDEMAR, J. P. de. (1977) Mobilidade do trabalho e acumulação do capital. 1. ed. Lisboa: Estampa.

GRESPAN, J. (2012) O negativo do capital: o conceito de crise na crítica de Marx à Economia Política. São Paulo: Expressão Popular.

GÓMEZ, S. (2011) Dinámica del mercado de la tierra en América Latina y el Caribe. Relatório de Pesquisa. Santiago: FAO.

HALL, R.; EDELMAN, M.; BORRAS Jr., S. M.; SCOONES, I.; WHITE, B.; WOLFORD, W. (2015) Resistance, acquiescense or incorporation? An introduction to land grabbing and political reactions "from below". The Journal of Peasant Studies, v. 42, n 3-4, p. 467-488.

HARVEY, D. (2005) A produção capitalista do espaço. 1. ed. São Paulo: Annablume.

(2015a) Capital's Nature - A response to Andrew Kliman. New Left Project. Disponível em:

<http://www.newleftproject.org/index.php/site/article_comments/capitals_naturea_response_ 
to_andrew_kliman>. Acessado em: 25 de out. de 2016.

Paulo: Loyola.

(1992) Condição pós-moderna: uma pesquisa sobre as origens da mudança cultural. São

(2015b) Crisis theory and the falling rate of profit. In: The Great Mealtdown of 2008: Systemic, Conjunctural or Policy-Created?. Londres: Edward Elgar Publishing Lmtd. Disponível em: <https://thenextrecession.files.wordpress.com/2014/12/harvey-on-Itrpf.pdf>. Acessado em: 25 de out. de 2016.

(2011) O enigma do capital e as crises do capitalismo. São Paulo: Boitempo.

(2013) O novo imperialismo. São Paulo: Edições Loyola.

(1982) The Limits to Capital. Oxford: Basil Blackwell.

HEIDEMANN, H. D.; TOLEDO, C. A; BOECHAT, C. A. (2014) O trabalho no Brasil: traçado interpretativo de sua história e de sua crítica. Estudos Avançados, IEA/USP, v. 28, n. 81.

HEINRICH, M. (2012) An Introduction to the Three Volumes of Karl Marx's Capital. Nova York: Monthly Review Press.

(2013) Crisis theory, the Law of the Tendency of the Profit Rate to Fall, and Marx's Studies in the 1870s. Monthly Review, v. 64, n. 11.

HILFERDING, R. (1985) O capital financeiro. São Paulo: Nova Cultural.

KLIMAN, A. (2015) Harvey versus Marx on capitalism's crisis. Part 1: Getting Marx Wrong. New Left Project. Disponível em: <http://www.newleftproject.org/index.php/site/article_comments/ harvey_versus_marx_on_capitalisms_crises_part_1_getting_marx_wrong>. Acessado em: 25 de out. de 2016.

Lexington.

(2007) Reclaiming Marx's "Capital": a refutation of the myth of inconsistency. Plymouth:

(2011) The Failure of Capitalist Production: underlying the causes of the Great Recession. Londres: Pluto Press.

KLIMAN, A.; FREEMAN, A.; POTTS, N.; GUSEV, A.; COONEY, B. (2013) The unmaking of Marx's Capital: Heinrich's attempt to eliminate Marx's crisis theory. In: MPRA Munich Personal RePEc Archive, n. 48535. Disponível em: <https://mpra.ub.uni-muenchen.de/48535/> . Acessado em: 25 de out. de 2016.

KURZ, R. (1995) A ascensão do dinheiro aos céus: os limites estruturais da valorização do capital, o capitalismo de casino e a crise financeira global. Disponível em: <o-beco.planetaclix.pt/ rkurz101.htm>. Acessado em: 25 de out. de 2016.

(2015) Dinheiro sem valor - linhas gerais para uma transformação da crítica da economia política. Lisboa: Antígona.

(2000) O colapso da modernização. 6. ed. São Paulo: Hucitec.

LENIN, V. I. (1979) O imperialismo: fase superior do capitalismo. São Paulo: Global.

LI, T. M. (2011) Centering labor in the land grab debate. The Journal of Peasant Studies, v. 38, n. 2, p. 281-298.

LUXEMBURGO, R. (1985) A acumulação do Capital: contribuição ao estudo do imperialismo. São Paulo: Nova Cultura.

MARX, K. (2005) Elementos fundamentales para la crítica de la economía política (Grundrisse): Borrador 1857-1858. Vol. I. 19a edição. Buenos Aires: Siglo Veintiuno Editores. 
economistas").

(1985) O Capital: crítica da Economia Política. Livro 1. São Paulo: Nova Cultural (Série “Os (1986) O Capital: crítica da Economia Política. Livro 3. São Paulo: Nova Cultural (Série “Os economistas").

MARGULIS, M. E.; MCKEON, N.; BORRAS JR., S. M. (2013) Land grabbing and global governance: critical perspectives. Globalizations, v. 10, n. 1, p. 1-23.

McMICHAEL, P. (2014) Rethinking land grab ontology. Rural Sociology, v. 79, n. 1, p. 34-55.

MELLO, G. M. de C. (2012) Teorias marxistas sobre o capitalismo. Doutorado. FFLCH, USP, São Paulo.

OYA, C. (2013) Methodological reflections on "land grab" databases and the "land grab" literature "rush". The Journal of Peasant Studies, v. 40, n. 3, p. 503-520.

PELUSO, N.; LUND, C. (2011) New frontiers of land control. The Journal of Peasant Studies, v. 38, n. 4, p. 667-681.

PITTA, F. T.; BOECHAT, C. A.; TOLEDO, C. A. (2016) A territorialização do capital da agroindústria canavieira paulista, ao longo do Proálcool (1975-1990). Revista Continentes (UFRRJ), ano 5, n. 9, p. 25-56.

PITTA, F. T.; MENDONÇA, M. L. (2015) A empresa Radar S/A e a especulação com terras no Brasil. São Paulo: Outras Expressões.

POSTONE, M. (2014) Tempo, trabalho e dominação social: uma reinterpretação da teoria crítica de Marx. São Paulo: Boitempo.

(2008) Teorizando o mundo contemporâneo - Robert Brenner, Giovanni Arrighi e David Harvey. Novos Estudos, n. 81, São Paulo.

PRADO, Eleutério F. S. (2014) Lei de Marx: pura lógica? Lei empírica? Revista da Sociedade Brasileira de Economia Política, n. 37, São Paulo.

(2011) O marxismo oracular de Robert Kurz. São Paulo. Retirado da página da internet, consultada em 29/10/2014. Disponível em: <http://eleuterioprado.files.wordpress.com/2011/11/o-marxismo-oracular-de-robert-kurz.pdf >. Acessado em: 25 de out. de 2016.

. (2012) O marxismo pé no chão de David Harvey. Cemarx, Campinas. Disponível em: <http:// www.ifch.unicamp.br/formulario_cemarx/selecao/2012/trabalhos/6248_Prado_Eleuterio.pdf >. Acessado em: 25 de out. de 2016:

RICARDO, D. (1982) Princípios de economia política e tributação. São Paulo: Abril Cultural (Os economistas).

ROBERTS, M. (2014) Monomania and crisis theory - a reply to David Harvey. Disponível em: <https://thenextrecession.wordpress.com/2014/12/17/david-harvey-monomaniacs-and-the-rate-of-profit/>. Acessado em: 25 de out. de 2016.

ROSDOLSKY, R. (2001) Gênese e estrutura de O capital de Karl Marx. Rio de Janeiro: EDUERJ/Contraponto.

SASSEN, S. (2010) A savage sorting of winners and losers: contemporary versions of primitive accumulation. Globalizations, v. 7, n. 1, p. 23-50.

dian.

(2013) Migration is expulsion by another name in the world of foreign land deals. The Guar-

(1990) The mobility of capital and labor: a study in international investment and labor flow.

Cambridge: Cambridge University Press. 
SAUER, S.; BORRAS JR., S. M. (2016) "Land grabbing" e "green grabbing": uma leitura da "corrida na produção acadêmica" sobre a apropriação global de terras. Campo-Território - Revista de Geografia Agrária. Edição Especial, p. 6-42.

SAUER, S.; LEITE, S. (2012) Agrarian structure, foreign investment in land, and land prices in Brazil. The Journal of Peasant Studies, v. 39, n. 3-4, p. 873-898.

SCOONES, I.; HALL, R.; BORRAS Jr., S. M.; WHITE, B.; WOLFORD, W. (2013) The politics of evidence: methodologies for understanding the global land rush. The Journal of Peasant Studies, v. 40, n. 3, p. 469-483.

SILVA, J. G. da. (1981). Progresso técnico e relações de trabalho na agricultura na agricultura. São Paulo: Hucitec.

TOLEDO, C. de A.; BOECHAT, C. A.; PITTA, F. T. (2013) Repensando o ajuste espacial. Anais do XVII Encontro de Geógrafos da América Latina. Lima, Peru.

WHITE, B.; BORRAS JR., S.; HALL, R; SCOONES, I.; WOLFORD, W. (2012) The new enclosures: critical perspectives on corporate land deals. The Journal of Peasant Studies, v. 39, n. 3-4, p. 619-647. 